MONOGRAF

ANALISIS KOMPARATIF MACHINE LEARNING UNTUK KLASIFIKASI \section{KEJADIAN STUNTING}

Monograf Analisis analisis komparasi Machine Learning untuk Klasifikasi Kejadian Stunting (balita atau anak yang bertubuh pendek) adalah memanfaatkan salah satu bidang kecerdasan buatan yaitu pembelajaran mesin dalam menganalisa kalsifikasi kejadian stunting yang saat ini kementrian kesehatan sedang promosi besar besaran dalam menangani stunting, karena permasalahan status gizi buruk yang saat ini terjadi di Indonesia. Dengan memanfaatkan pemebelajaran mesin melalui penedekatan klasifikasi menggunakan tiga algortima yaitu; Decision Tree, Naïve Bayes, dan K Nearest Neighbor.

Hasil dari tiga algoritma tersebut nantinya memberikan rekomendasi kepada pakar-pakar di bidang kesehatan khususnya yang menangani penyakit stunting, yang dapat dilihat dari kondisi orang tua, kemudian kodisi balita serta pemberian asi yang cukup. Didalam pengelolaan data set stunting menggunakan tools dengan software opensource yaitu rapidminer, penggunaan software tersebut sangat mudah digunakan. Silahkan download di https://rapidminer.com.

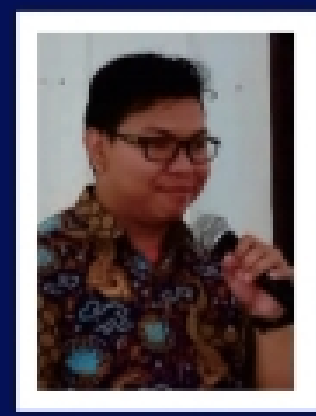

Agus Byna menyelesaikan studi mulai jenjang diploma 2 di Lembaga Pendidikan dan Pengembangan Profesi Indonesia (LP3i) Banjarmasin kemudian melanjutkan diploma 3 di Politeknik Lp3i Bandung, menyelsaikan studi S1 di STIMIK Bandung mengambil Jurusan Sistem Informasi dan Studi S2 di Univeristas Dian Nuswantoro Semarang Mengambil Jurusan Teknik Informatika. Sebagai Dosen di jurusan Sistem Informasi Universitas Sari Mulia Banjarmasin, Serta mendapatkan hibah penelitian dosen pemula (PDP) dari ementerian Riset dan Teknologi / Badan Riset dan Inovasi Nasional Republik Indonesia (ristekdikti) sebanyak dua kali ; yang pertama pada tahun 2018 dan yang terakhir 2020.
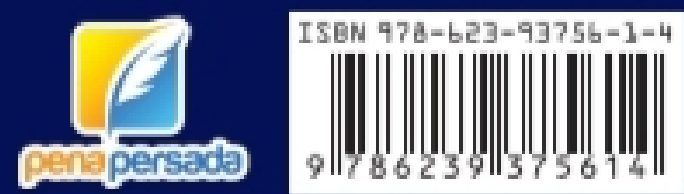

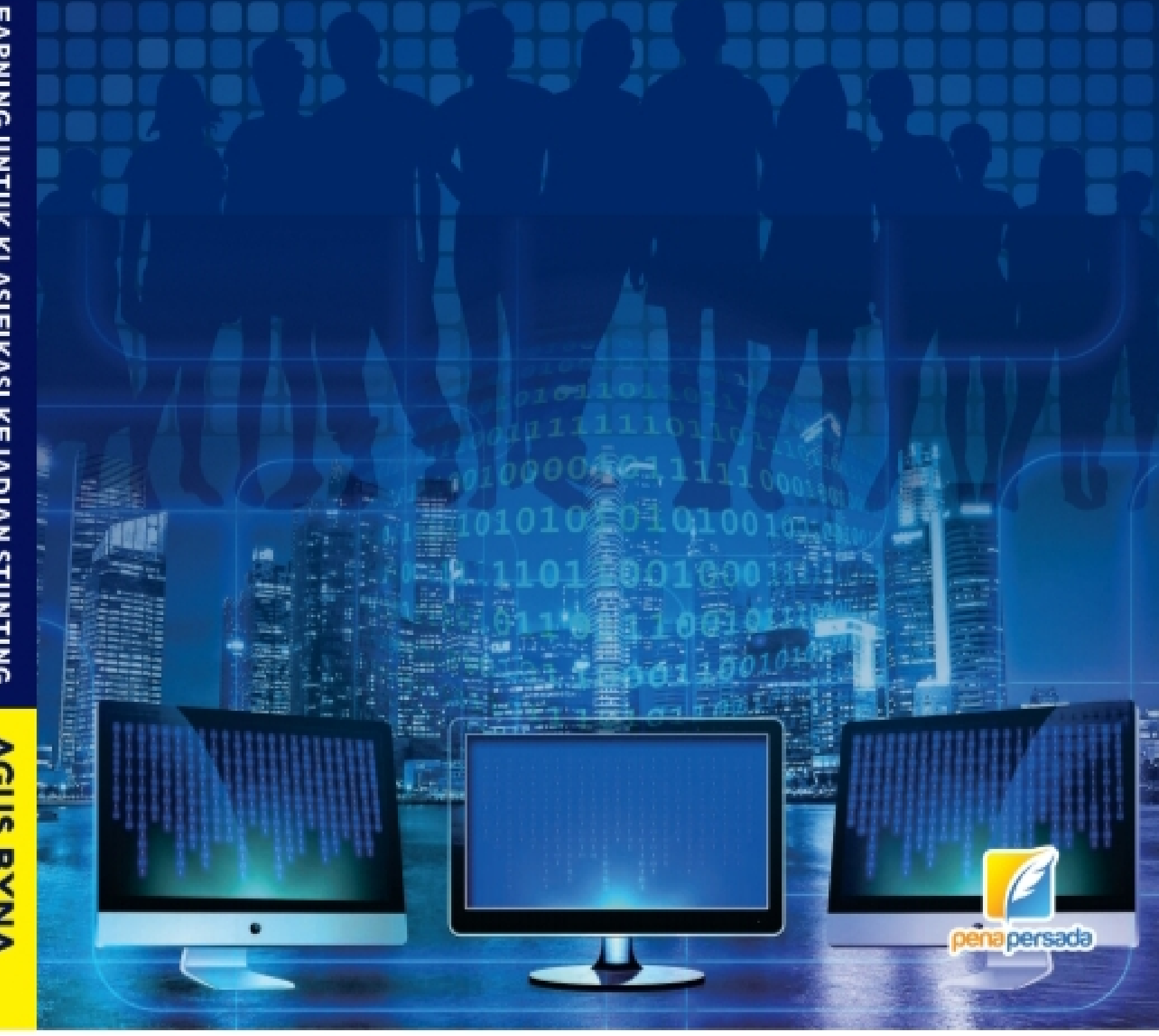




\section{MONOGRAF \\ ANALISIS KOMPARATIF \\ MACHINE LEARNING UNTUK \\ KLASIFIKASI KEJADIAN STUNTING}

Agus Byna

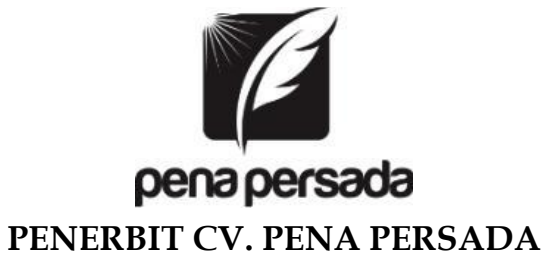




\section{MONOGRAF \\ ANALISIS KOMPARATIF MACHINE LEARNING UNTUK KLASIFIKASI KEJADIAN STUNTING}

Penulis:

Agus Byna

ISBN : 978-623-93756-1-4

Design Cover :

Retnani Nur Briliant

Layout :

Nisa Falahia

\section{Penerbit CV. Pena Persada}

Redaksi :

Jl. Gerilya No. 292 Purwokerto Selatan, Kab. Banyumas

Jawa Tengah

Email : penerbit.penapersada@gmail.com

Website : penapersada.com

Phone : (0281) 7771388

\section{Anggota IKAPI}

All right reserved

Cetakan pertama : 2020

Hak cipta dilindungi oleh undang-undang. Dilarang

memperbanyak karya tulis ini dalam bentuk apapun tanpa ijin

penerbit 


\section{KATA PENGANTAR}

Dengan mengucapkan puji syukur kehadirat Allah SWT Yang Maha Esa, atas berkat dan rahmat-Nya sehingga penulis dapat menyelesaikan penyusunan buku monograf yang berjudul "Analisis Komparasi Machine Learning untuk klasifikasi kejadian Stunting".

Buku monograf ini diharapkan bisa menjadi tambahan referensi bagi para akademisi dan masyarakat pada umumnya dalam rangka menambah khasanah pengetahuan bidang kesehatan dan computer sains.

Penulis tentunya menyadari bahwa dalam penulisan buku monograf ini masih banyak kekuarangan sehingga saran dan kritik diterima dengan lapang. Terakhir, semoga buku monograf ini memberikan manfaat bagi semua. Aamiin.

Banjarmasin, Mei 2020

Penulis 


\section{DAFTAR ISI}

KATA PENGANTAR ............................................................... iii

DAFTAR ISI ........................................................................... iv

ABSTRAKS ….................................................................... v

ABSTRACT ….......................................................................... vi

BAB I

PENDAHULUAN ....................................................................... 1

A. Latar Belakang................................................................. 1

B. Rumusan Masalah ............................................................. 4

C. Tujuan Penelitian ............................................................... 4

D. Manfaat Penelitian .......................................................... 4

BAB II

TINJAUAN PUSTAKA ............................................................... 6

A. Landasan Teori.................................................................. 6

B. Penelitian Terdahulu ...................................................... 20

BAB III

METODE PENELITIAN ......................................................... 21

A. Lokasi Penelitian ........................................................... 21

B. Jenis dan Sumber Data .................................................. 21

C. Teknik Pengumpulan Data............................................. 21

D. Analisa Data ............................................................... 22

E. Kerangka Penelitian......................................................... 22

BAB IV

HASIL DAN PEMBAHASAN .................................................. 24

A. Tahapan Hasil Penelitian .................................................. 24

B. Metode Pengumpulan Data .......................................... 24

C. Metode Pengolahan Data Awal ...................................... 25

D. Hasil Pengujian Model/Metode .................................... 26

E. Analisa Evaluasi Dan Validasi Hasil.............................. 38

BAB V

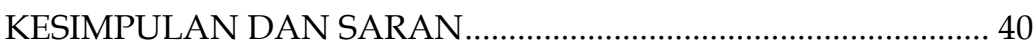

A. Kesimpulan ...................................................................... 40

B. Saran .................................................................................. 40

DAFTAR PUSTAKA ................................................................. 41 


\begin{abstract}
ABSTRAKS
Latar Belakang Penggunaan pembelajaran mesin sangat dibutuhkan oleh para ahli kesehatan sebagai pengolahan data dan informasi agar lebih mudah dianalisis secara otomatis sehingga menghasilkan akurasi dalam menyelesaikan masalah, penerapan Machine Learning dengan algoritma 3 komparatif untuk menyelesaikan masalah stunting karena balita di Indonesia masih tinggi, terutama pada usia $2-3$ tahun. Terlihat dari sejumlah faktor yang berisiko menyebabkan stunting. Instrumen diperlukan dalam Pembelajaran Mesin. Tujuannya (1). Selain memberikan pengetahuan di bidang Informatika, hal ini juga berguna bagi para pakar kesehatan dalam mengelola data dalam mengambil keputusan sehingga memudahkan serta analisis secara otomatis. (2) Dapat mengurangi dampak pada kejadian stunting. Metode Perbandingan tiga algoritma dalam klasifikasi hasil dari tiga algoritma yang dibandingkan menghasilkan akurasi $87.91 \%$ AUC 0,907 untuk algoritma Decision Tree dengan tingkat diagnosis excellent classification, dari Algoritma KNN dan Algoritma Naïve Bayes yang menggunakan 13 variabel data.

Kata kunci: Kejadian Stunting, Pohon Keputusan, KNN, Naïve Bayes, Pembelajaran Mesin.
\end{abstract}




\begin{abstract}
Background The use of machine learning is urgently needed by health experts as data and information processing to make it easier to analyze automatically so that it produces accuracy in solving problems, the application of Machine Learning with a comparative 3 algorithm to solve stunting problems because toddlers in Indonesia are still high, especially at the age 23 years. Seen from many factors that are at risk of causing stunting. Instruments needed in Machine Learning. The goal (1). In addition to providing knowledge in the field of Informatics, it is also useful for health experts in managing data in making decisions to facilitate and analyze automatically. (2) It can reduce the impact on stunting events. Method Comparison of the three algorithms in the classification of the results of the three algorithms compared produces an accuracy of $87.91 \%$ AUC 0.907 for the Decision Tree algorithm with a diagnosis level of excellent classification, from the KNN Algorithm and the Naïve Bayes Algorithm using 13 data variables.
\end{abstract}

Keywords: Genesis Stunting, Decision Tree, KNN, Naïve Bayes, Machine Learning. 


\section{BAB I \\ PENDAHULUAN}

\section{A. Latar Belakang}

Dalam Bidang kesehatan yang secara luas sudah mengenal informasi data, data tersebut semakin banyak yang tersimpan di sebuah database kemudian data tersebut dapat di kelola kembali melalui bidan ilmu yaitu Machine Learning (Pembelajaran Mesin), hasil dari pembelajaran mesin bisa di gunakan dalam mengembangkan aplikasi pintar dan sistem pakar yang dapat memberikan informasi lebih akurat.

Contohnya didalam data rekam medis, didalam pengelolaannya sudah menggunakan beberapa teknik tersebut pada beberapa kasus yang ada seperti klasifikasi, prediktif, dan klustering yang masuk didalam Supervised Learning (sebuah pendekatan dimana sudah terdapat data yang dilatih, dan terdapat variable yang ditargetkan sehingga tujuan dari pendekatan ini adalah mengkelompokan suatu data ke data yang sudah ada). (Huddleston \& Brown, 2018)

Banyak kasus yang diberikan untuk kontribusi di bidang kesehatan tersebut diantaranya yaitu dengan menggunakan Algortima Naïve Bayes classification (NBC), teknik data mining Decision Tree, dan teknik Neural Network, serta Support Vector Machine. Penerapan data mining sangat di perlukan dalam bidang kesehatan sebagai inovasi dalam mengambil keputusan yang akurat sehingga bermanfaat untuk pengembangan informasi diberikan menjadi lebih akurat. (Haridas \& Wilson, 2018)

Khususnya dalam kejadian stunting yaitu mempunyai permasalahan gizi yang kronis sehingga membutuhkan penanganan yang tepat. Saat melakukan penanganan perlu diketahui faktor risiko stunting diantaranya yaitu frekuensi kunjungan posyandu dan kenaikan berat badan (Destiadi et al., 2015). 
Stunting adalah masalah gizi di dunia, terutama terjadi di negara-negara berkembang. Stunting dapat meningkatkan risiko morbiditas dan mortalitas, serta perkembangan otak sub optimal sehingga memperlambat perkembangan motorik dan keterbelakangan mental. Stunting Adalah bentuk kegagalan pertumbuhan karena akumulasi kecukupan gizi sejak awal kehamilan hingga 24 bulan. Situasi ini diperburuk oleh pertumbuhan catch-up yang tidak memadai.(Lppm et al., 2015)

Jumlah anak mengalami kejadian stunting sangat banyak yang dapat memberikan dampak indikasi di masyarakat, masalah ini berlangsung cukup lama. Kejadian stunting dipengaruhi oleh banyak faktor diantaranya pemberian ASI eksklusif. Masalah kesehatan masyarakat dianggap berat bila prevalensi pendek sebesar 30-39 persen dan serius bila prevalensi pendek $\geq 40$ persen(WHO, 2016).

Banyak sekali para peneliti terutama pakar kesehatan menggunakan data mining sebagai pemanfaatan dalam mencari solusi yang terbaik dalam penanganan suatu penyakit. Penggunaan Algoritma di bantu dengan beberapa metode yang menghasilkan akurasi dalam prediksi menjadi akurat.

Dengan memanfaatkan keilmuan di bidang Informatika di terapkan di bidang kesehatan dalam pengelolaan data yang memberikan hasil didalam mengambil keputusan. Penggunaan optimasi Backward Elimination dengan algortima Support Vector Machine memberikan nilai sebesar $90.16 \%$ dan nilai AUC sebesar 0,962 dengan tingkat diagnosa Excelent Classification. Penerapan metode Backward Elimination dapat meningkatkan nilai akurasi pada algoritma SVM dan juga menseleksi atrribut/variable.(Byna \& Anisa, 2018)

Dalam hasil penelitian yang dilakukan pada data pasien penderita penyakit hepatitis menggunakan metode klasifikasi data mining melakukan perbandingan antara Algoritma C4.5 menghasilkan akurasi $77,29 \%$ dan nilai AUC 0,846 dan Algoritma Naive Bayes menghasilkan akurasi 83,71\% dan nilai AUC 0,812 sehingga kedua metode ini akurat dalam melakukan prediksi untuk penyakit hepatitis (Septiani, 2017). 
Pemanfaatan Machine Leraning tidak hanya di gunakan dalam klasifikasi data, ada manfaat lain dalam mendiagnosis penyakit berbentuk sebuah aplikasi yaitu aplikasi diagnosis tingkat risiko penyakit stroke menggunakan metode K-Nearest Neighbor dan Naïve Bayes karena data yang didapat menggunakan atribut numerik dan kategoris. Algoritme KNearest Neighbor digunakan untuk memproses data numerik, dan algoritme Naïve Bayes digunakan untuk memproses data kategori. Hasil penelitian menunjukkan nilai akurasi tertinggi yang diperoleh pada data kelas seimbang adalah 96.67\% dengan data latih 45 , data uji 30 dan nilai $K=15-22$. Sedangkan pada data latih tidak seimbang, menunjukkan akurasi tertinggi sebesar $100 \%$ dengan jumlah data latih 60, data uji 30 dan nilai $\mathrm{K}=20-30$.(Puspitawuri et al., 2019)

Pemanfataan lagi yang digunakan di bidang ilmu kebidanan dalam memprediksi penyakit ibu habis yang Diperolehnya informasi dalam menerapkan optimasi particle swarm optimization pada algoritma ID3 (Iterative Dichotomiser Three) untuk meningkatkan keakuratan dalam memprediksi penyakit pre eklampsia pada ibu hamil. Data latih dan testing menghasilkan tingkat akurasi sebesar $93.33 \%$ dengan AUC sebesar 0,906 dari Algortima ID3 dengan optimasi Particle Swarm Optimization hasil tingkat diagnosanya adalah diagnosa Excelent Classification. Dari hasil kedua metode memiliki perbedaan mulai dari tingkat akurasi 3,07\% kemudian AUC 0,049.(Byna Agus, 2019)

Berdasarkan latar belakang di atas penulis tertarik melakukan analisis menggunakan Machine Learning dengan tahap Supervised Learning yang didalamnya menggunakan tiga algoritma klasifikasi yaitu Decision Tree, Naïve Bayes, dan knearest neighbors dengan data tentang kejadian stunting dalam mengkomparasi algortima yang lebih baik. 


\section{B. Rumusan Masalah}

Berdasarkan latar belakang diatas untuk mengetahui penerapan Machine Learning dengan mengkomparasi dari tiga algoritma klasifikasi yaitu yaitu Decision Tree, Naïve Bayes, dan k-nearest neighbors dapat memberikan akurasi yang akurat dalam memprediksi kejadian stunting di puskesmas banjarmasin.

\section{Tujuan Penelitian}

Tujuan dari penelitian ini yaitu:

1. Untuk pakar kesehatan agar dapat mengetahui pengelolan data secara khusus tentang kejadian stunting yang dapat dilakukan untuk mengatasi masalah tersebut dengan memberikan hasil keputusan yang tepat.

2. Untuk memberikan informasi yang akurat bagi masyarakat terutama tentang kejadian stunting.

3. Memberikan kontribusi kepada kampus-kampus kesehatan didalam mengelola data tentang kejadian stunting.

\section{Manfaat Penelitian}

Berdasarkan tujuan penelitian yang hendak dicapai, maka penelitian ini diharapkan mempunyai manfaat dalam pendidikan baik secara langsung maupun tidak langsung. Adapun manfaat penelitian ini adalah sebagai berikut :

1. Manfaat teoritis

Secara teoritis hasil penelitian ini diharapkan dapat bermanfaat yaitu:

a. Memberikan sumbangan pemikiran bagi pembaharuan kurikulum di bidang kesehatan dan Informatika yang berkembang sesuai dengan tuntutan masyarakat dan sesuai dengan kebutuhan di dunia medis dan informasi.

b. Memberikan sumbangan ilmiah dalam ilmu kedokteran dan Informatika computer yang terus berkembang.

c. Sebagai pijakan dan referensi pada penelitian-penelitian selanjutnya yang berhubungan dengan Machine Learning dalam mengelola data penyakit. 
2. Manfaat praktis

Secara praktis penelitian ini dapat bermanfaat sebagai berikut :

a. Bagi penulis

Dapat menambah wawasan dan pengalaman langsung tentang cara memanfaatkan salah satu cabang dari kecerdasan buatan yaitu pembelajaran mesin di dalam pengelolaan data-data kesehatan.

b. Bagi pendidik dan calon pendidik

Dapat menambah pengetahuan dan sumbangan pemikiran tentang cara mengembangkan kemampuan sains khususnya melalui dalam pengelolaan data secara tepat waktu dalam meberikan solusi berupa keputusan.

c. Bagi Perguruan Tinggi

Sebagai bahan pertimbangan dalam menyusun program pembelajaran serta menentukan metode dan media pembelajaran yang tepat untuk mengembangkan penelitian yang lebih lanjut melalui pemanfaatan data. 